\title{
Changes in the TBARs content and superoxide dismutase, catalase and glutathione peroxidase activities in the lymphoid organs and skeletal muscles of adrenodemedullated rats
}

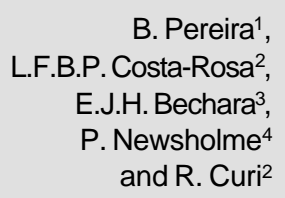

B. Pereira ${ }^{1}$,

L.F.B.P. Costa-Rosa ${ }^{2}$,

E.J.H. Bechara ${ }^{3}$,

P. Newsholme 4 and R. Curi ${ }^{2}$

\author{
${ }^{1}$ Departamento de Biodinâmica, Escola de Educação Física e Esportes, \\ 2Departamento de Fisiologia e Biofísica, Instituto de Ciências Biomédicas, \\ and ${ }^{3}$ Departamento de Bioquímica, Instituto de Química, Universidade de \\ São Paulo, São Paulo, SP, Brasil \\ ${ }^{4}$ Department of Biochemistry, University College Dublin, Dublin, Ireland
}

\section{Correspondence \\ R. Curi \\ Departamento de Fisiologia e \\ Biofísica, ICB, USP \\ Av. Professor Lineu Prestes, 1524 \\ 05508-900 São Paulo, SP \\ Brasil}

Research supported by FAPESP, CNPq, PRONEX (168/97), and the British Council.

.....................

Received August 6, 1997 Accepted March 4, 1998

\section{Abstract}

Thiobarbituric acid reactant substances (TBARs) content, and the activities of glucose-6-phosphate dehydrogenase (G6PDh), citrate synthase (CS), $\mathrm{Cu} / \mathrm{Zn}$ - and $\mathrm{Mn}$-superoxide dismutase (SOD), catalase, and glutathione peroxidase (GPX) were measured in the lymphoid organs (thymus, spleen, and mesenteric lymph nodes (MLN)) and skeletal muscles (gastrocnemius and soleus) of adrenodemedullated $(\mathrm{ADM})$ rats. The results were compared with those obtained for shamoperated rats. TBARs content was reduced by adrenodemedullation in the lymphoid organs (MLN (28\%), thymus (40\%) and spleen (42\%)) and gastrocnemius muscle (67\%). G6PDh activity was enhanced in the MLN (69\%) and reduced in the spleen (28\%) and soleus muscle (75\%). CS activity was reduced in all tissues (MLN (75\%), spleen (71\%), gastrocnemius $(61 \%)$ and soleus $(43 \%))$, except in the thymus which displayed an increment of $56 \%$. Cu/Zn-SOD activity was increased in the MLN (126\%), thymus (223\%), spleen $(80 \%)$ and gastrocnemius muscle $(360 \%)$ and was reduced in the soleus muscle (31\%). Mn-SOD activity was decreased in the MLN (67\%) and spleen (26\%) and increased in the thymus (142\%), whereas catalase activity was reduced in the MLN (76\%), thymus (54\%) and soleus muscle $(47 \%)$. It is particularly noteworthy that in ADM rats the activity of glutathione peroxidase was not detectable by the method used. These data are consistent with the possibility that epinephrine might play a role in the oxidative stress of the lymphoid organs. Whether this fact represents an important mechanism for the establishment of impaired immune function during stress remains to be elucidated.
Key words

- Epinephrine

- Lymphoid organs

- Superoxide dismutase

- Catalase

- Glutathione peroxidase

- TBARs 


\section{Introduction}

Oxygen free radicals (superoxide, $\left[\mathrm{O}_{2}^{-}\right]$and hydroxyl radical $\left.\left[\mathrm{OH}^{*}\right]\right)$ and hydrogen peroxide $\left(\mathrm{H}_{2} \mathrm{O}_{2}\right)$, called reactive oxygen species (ROS), play a significant role in the antibacterial and antitumorigenic capacity of macrophages and neutrophils, but they are also capable of presenting a toxic action on self tissues causing lipid peroxidation $(1,2)$. In fact, the deficiency of vitamin $\mathrm{E}$ has been reported to facilitate the increase in ROS concentrations leading to functional changes in the immune system $(1,3)$. For instance, chemical antioxidants such as B-carotene (4), vitamin E (5), vitamin C (6) and reduced glutathione (GSH) (7) improve the proliferative capacity of lymphocytes, and increase host defense and immunoglobulin synthesis (8). Evidence has been presented that stress may influence the function of the immune system of humans and experimental animals (9) and modify the pro-oxidant capacity of macrophages and neutrophils. These effects may cause a decrease in the function of these cells and modify the immune response to viruses and bacteria. Most of the investigations on this subject have focused on the role of glucocorticoids (10-12). Indeed, glucocorticoids present a high capacity for inhibition of ROS production by macrophages and neutrophils (13). However, during stress the sympathetic nervous system is stimulated and epinephrine is secreted from the adrenal medulla (14). Furthermore, as is the case for all cells responsive to epinephrine via cAMP generation, immune cells display $\beta-$ adrenoceptors $(15,16)$. In fact, epinephrine increases the proliferative capacity of CD4+ and CD8+ cells via $\alpha$-receptors, but inhibits that of $\mathrm{CD} 4+$ cells via $\beta$ adrenoceptors (17-19). Thus, it was proposed that when cAMP concentrations increase in the lymphocytes, the proliferative capacity of the latter is inhibited (20). Cannon (21) suggested that cAMP might not be considered only an immune inhibitory agent. Munck et al. (22) also reported that "the increase in the concentration of cortisone in the plasma during prolonged exercise may serve to protect the body against the excessive activation of its immune defenses during stress". This means that epinephrine may act as a modulating agent of human immunity, in addition to glucocorticoids.

Recent work from our laboratory has shown that epinephrine stimulates $\mathrm{H}_{2} \mathrm{O}_{2}$ production in incubated rat macrophages (23). However, the effect of epinephrine observed in vitro does not imply that this hormone plays a physiological role for the control of immune function. In addition, whether the generation of $\mathrm{H}_{2} \mathrm{O}_{2}$ by epinephrine is linked to changes in the activity of antioxidant enzymes remains unknown. Taking into account the involvement of ROS in the immune function, it is important to investigate the effect of epinephrine on antioxidant enzyme activities, the major form of cell defense against acute oxygen toxicity (24), and lipid peroxidation. In the present study, the physiological effect of epinephrine (by bilateral removal of adrenal medulla (ADM)) on the activity of superoxide dismutase (SOD), catalase and glutathione peroxidase (GPX) of the lymphoid organs (mesenteric lymph nodes (MLN), spleen and thymus) was examined. For comparison with nonimmune tissues, skeletal muscles (soleus and gastrocnemius) were also studied. Enzyme activities involved in the generation of reducing power were also measured: glucose-6-phosphate dehydrogenase (G6PDh), indicative of the flux of substrates through the pentose-phosphate pathway (25), and citrate synthase (CS), an indicator of the flux of substrates through the Krebs cycle (26). As an indication of the occurrence of lipid peroxidation under these conditions, the content of thiobarbituric acid reactant substances (TBARs) was also determined. 


\section{Material and Methods}

\section{Reagents and equipment}

All chemicals and enzymes were obtained from Sigma Chemical Co. (St. Louis, MO) and Boehringer Mannheim (Germany). The solutions were prepared with twice-distilled, Millipore Milli Q deionized water. All measurements were performed using Zeiss DMR10 and Gilford (Model Response) spectrophotometers.

\section{Animals}

Male Wistar rats weighing $180 \mathrm{~g}$ (about 2 months of age) were obtained from the Institute of Biomedical Sciences. The rats were maintained at $23^{\circ} \mathrm{C}$ on a 12 -h light: 12 -h dark cycle.

\section{Adrenodemedullation}

The rats were anesthetized by ether inhalation and the kidneys were exposed through the dorsal side. A small cut in the cortex of the adrenal glands was made so that the medulla could be removed by light pressure on the gland. Enzyme activities and lipid peroxidation were measured 35 days after adrenodemedullation. A similar procedure has been previously used (27).

\section{Experimental procedure}

The rats were always killed between 8:00 and 11:00 a.m. by cervical dislocation without anesthesia. The thymus, spleen, MLN, gastrocnemius (white portion, type IIb fibers) and soleus (type I fibers) muscles were then excised and maintained in liquid nitrogen prior to measurements of the enzyme activities and TBARs content.

\section{Enzymeassays}

The extraction medium for the measure- ments of $\mathrm{Cu} / \mathrm{Zn}$ - and $\mathrm{Mn}-\mathrm{SOD}$, catalase and GPX activities contained $0.10 \mathrm{M}$ sodium phosphate, $\mathrm{pH}$ 7.0. For the SOD assay (28), the homogenate was centrifuged at 10,000 $g$ for $30 \mathrm{~min}$. $\mathrm{Cu} / \mathrm{Zn}$ - and $\mathrm{Mn}-\mathrm{SOD}$ activities were measured by following the dismutation of $\mathrm{KO}_{2}$ at $250 \mathrm{~nm}$. The procedures used for catalase and GPX assays were similar to those used by Beutler (29) and Maral et al. (30), respectively. Catalase activity was determined by measuring the decomposition of hydrogen peroxide at $230 \mathrm{~nm}$. GPX activity was measured by following the rate of oxidation of the reduced form of glutathione. The formation of oxidized glutathione was monitored by a decrease in the concentration of NADPH, measured at $340 \mathrm{~nm}$, due to the addition of glutathione reductase to the medium.

The extraction medium for $\mathrm{CS}$ and G6PDh contained $50 \mathrm{mM}$ Tris- $\mathrm{HCl}$ and $1 \mathrm{mM}$ EDTA, $\mathrm{pH}$ 7.4. CS was assayed as described by Cooney et al. (31) and G6PDh according to Bergmeyer and Bernt (32). The assay medium for CS consisted of $100 \mathrm{mM}$ Tris- $\mathrm{HCl}$, $0.2 \mathrm{mM} 5,5$ '-dithio-bis-2-nitrobenzoic acid, $15 \mathrm{mM}$ acetyl-CoA, and $0.5 \mathrm{mM}$ oxaloacetate, $\mathrm{pH}$ 8.1. The assay medium for G6PDh consisted of $86 \mathrm{mM}$ Tris- $\mathrm{HCl}, 6.9 \mathrm{mM} \mathrm{MgCl}_{2}$, $0.4 \mathrm{mM}$ NADP, $1.2 \mathrm{mM}$ glucose-6-phosphate, and 1.2 U/ml 6-phosphogluconate dehydrogenase, $\mathrm{pH}$ 7.6. All spectrophotometric measurements were carried out at $25^{\circ} \mathrm{C}$. The enzyme activities are reported as $\mu \mathrm{mol} / \mathrm{min}$ per $\mathrm{g}$ tissue fresh weight.

\section{Determination of TBARs}

Substances that react with TBARs were measured as described by Winterbourn et al. (33) in the same extraction medium as for the antioxidant enzyme assays.

\section{Statistical analysis}

Two-way ANOVA with post hoc contrasts was used to compare groups. The level of significance was set at $\mathrm{P}<0.01$. 
Table 1 - Content of thiobarbituric acid-reactive substances (TBARs) in the lymphoid organs and muscles of adrenodemedullated (ADM), sham-operated and control rats.

Values are reported as means \pm SEM for 8 rats in each group. ${ }^{*} \mathrm{P}<0.01$ for comparison between $\mathrm{ADM}$ and sham-operated rats (Student $t$-test). MLN, Mesenteric lymph nodes; GC, gastrocnemius white portion.

\begin{tabular}{lcrr}
\hline & Control & $\begin{array}{c}\text { Sham-operated } \\
(\mu \mathrm{mol} / \mathrm{g} \text { tissue fresh weight) }\end{array}$ & \multicolumn{1}{c}{ ADM } \\
\hline MLN & $10.1 \pm 2$ & $8.5 \pm 0.8$ & $6.1 \pm 0.3^{*}$ \\
Thymus & $13.2 \pm 2$ & $15.4 \pm 1.2$ & $9.2 \pm 0.6^{*}$ \\
Spleen & $39.3 \pm 5$ & $42.0 \pm 4.5$ & $24.2 \pm 8.4^{*}$ \\
GC & $4.8 \pm 0.3$ & $5.4 \pm 0.4$ & $1.8 \pm 0.03^{*}$ \\
Soleus & $6.5 \pm 0.4$ & $6.5 \pm 0.5$ & $7.5 \pm 0.4$
\end{tabular}

Table 2 - Glucose-6-phosphate dehydrogenase (G6PDh) activity in the lymphoid organs and muscles of adrenodemedullated (ADM), sham-operated and control rats.

Values are reported as means \pm SEM for 8 rats in each group. ${ }^{*} \mathrm{P}<0.01$ for comparison between $\mathrm{ADM}$ and sham-operated rats (Student $t$-test). MLN, Mesenteric lymph nodes; GC, gastrocnemius white portion.

\begin{tabular}{|c|c|c|c|}
\hline & \multicolumn{3}{|c|}{$\left(\mu \mathrm{mol} \min ^{-1} \mathrm{~g}\right.$ tissue fresh weight $\left.{ }^{-1}\right)$} \\
\hline MLN & $14.3 \pm 1.4$ & $13.6 \pm 1.3$ & $22.7 \pm 2.5^{*}$ \\
\hline Thymus & $21.3 \pm 1.9$ & $22.8 \pm 3.3$ & $22.5 \pm 2.7$ \\
\hline Spleen & $54.7 \pm 5.6$ & $51.9 \pm 4.3$ & $36.1 \pm 2.4^{*}$ \\
\hline GC & $4.4 \pm 0.2$ & $4.8 \pm 0.3$ & $3.7 \pm 0.3$ \\
\hline Soleus & $6.4 \pm 0.6$ & $6.3 \pm 0.6$ & $2.1 \pm 0.1^{*}$ \\
\hline
\end{tabular}

Table 3 - Citrate synthase (CS) activity in the lymphoid organs and muscles of adrenodemedullated (ADM), sham-operated and control rats.

Values are reported as means \pm SEM for 8 rats in each group. ${ }^{*} \mathrm{P}<0.01$ for comparison between $\mathrm{ADM}$ and sham-operated rats (Student $t$-test). MLN, Mesenteric lymph nodes; GC, gastrocnemius white portion.

\begin{tabular}{|c|c|c|c|}
\hline & \multicolumn{3}{|c|}{ 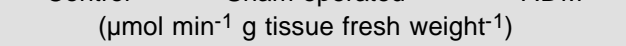 } \\
\hline MLN & $107.3 \pm 8$ & $101.2 \pm 5.3$ & $25.2 \pm 1.2^{*}$ \\
\hline Thymus & $15.4 \pm 1.2$ & $13.9 \pm 1.0$ & $21.7 \pm 1.5^{*}$ \\
\hline Spleen & $71.9 \pm 4.7$ & $73.2 \pm 0.8$ & $21.0 \pm 0.7^{*}$ \\
\hline GC & $54.2 \pm 2.8$ & $56.8 \pm 4.1$ & $21.9 \pm 1.6^{*}$ \\
\hline Soleus & $55.4 \pm 2.3$ & $56.8 \pm 4.1$ & $32.0 \pm 0.2^{*}$ \\
\hline
\end{tabular}

\section{Results}

The results for sham-operated rats did not differ from those obtained in controls. Thus, the results for adrenodemedullated rats were compared with those of sham-operated rats only. The content of TBARs (Table 1) was diminished by adrenodemedullation in the lymphoid organs (mesenteric lymph nodes $(28 \%)$, thymus $(40 \%)$ and spleen $(42 \%))$ and gastrocnemius muscle $(67 \%)$. In relation to the sites of production of reducing power, G6PDh activity (Table 2) was enhanced in the MLN (69\%) and reduced in the spleen $(28 \%)$ and soleus muscle $(75 \%)$ due to removal of the adrenal medulla. CS activity (Table 3) was lowered in all tissues (MLN (75\%), spleen $(71 \%)$, gastrocnemius $(61 \%)$ and soleus (43\%)), except in the thymus which displayed an increment of 56\% as a consequence of the absence of the adrenal medulla.

The antioxidant enzyme activities were also markedly changed by the removal of the adrenal medulla. $\mathrm{Cu} / \mathrm{Zn}-\mathrm{SOD}$ activity (Table 4) was increased in the MLN (126\%), thymus $(223 \%)$, spleen $(80 \%)$ and gastrocnemius muscle (360\%) and was reduced in the soleus muscle $(31 \%)$. Removal of the adrenal medulla decreased Mn-SOD activity in the MLN (67\%) and spleen (26\%) and increased it in the thymus (142\%) (Table 5), whereas catalase activity was lowered in the MLN (76\%), thymus (54\%) and soleus muscle (47\%) (Table 6). It is particularly noteworthy that in ADM rats the activity of glutathione peroxidase was not detectable by the method used for all tissues studied (Table 7).

\section{Discussion}

Whether epinephrine plays a role for the establishment of an impaired immune response as reported for several modalities of stress is an intriguing point. In this study, changes in the oxygen metabolism of the 
lymphoid organs (mesenteric lymph nodes, thymus and spleen) were investigated by the removal of the adrenal medulla. This experimental procedure was chosen in order to avoid possible misinterpretation of the results that may occur in pharmacological experiments (e.g. administration of adrenergic drugs). The results were compared with those obtained for skeletal muscle.

Taken as a whole, the effect of adrenodemedullation on TBARs content and enzyme activities in the lymphoid organs was not markedly different from that observed in the skeletal muscles.

The removal of adrenal medulla reduced the content of TBARs as shown in Table 1. Therefore, circulating catecholamines may play a role in the lipid peroxidation process. Catecholamines may increase the content of TBARs due to stimulation of the activities of enzymes involved in the sites of production of the reducing power required for NADPH oxidase activity (pentose-phosphate pathway and Krebs cycle) or by inhibition of antioxidant enzyme activities. These possibilities were examined in the present study. The removal of the adrenal medulla produced tissue-specific effects on G6PDh activities. This enzyme can provide a qualitative index of NADPH production via the pentose-phosphate pathway. There was an increase in G6PDh activity in the MLN and a reduction in the soleus muscle and spleen. However, adrenodemedullation provoked a marked decrease of CS activity in all tissues studied except the thymus (Table 3). This decrease was particularly marked for the MLN and spleen, suggesting a lower flux through the TCA cycle in cells of the lymphoid tissues, in the absence of adrenaline (26). Lymphoid cells may compensate for this change by increasing ATP synthesis via anaerobic glycolysis while also decreasing flux through the pentose-phosphate pathway (as a consequence of maximizing carbon flux through the ATP generating reactions of glycolysis). In fact, in our previous study it was found
Table 4 - Cu/Zn-superoxide dismutase (Cu/Zn-SOD) activity $\left(x 10^{3}\right)$ in the lymphoid organs and muscles of adrenodemedullated (ADM), sham-operated and control rats.

Values are reported as means \pm SEM for 8 rats in each group. ${ }^{*} \mathrm{P}<0.01$ for comparison between $\mathrm{ADM}$ and sham-operated rats (Student $t$-test). MLN, Mesenteric lymph nodes; GC, gastrocnemius white portion.

\begin{tabular}{lccc}
\hline & $\begin{array}{c}\text { Control } \\
\left(\mu \mathrm{mol} \mathrm{min}^{-1} \mathrm{~g} \text { tissue fresh weight }{ }^{-1}\right)\end{array}$ \\
& \multicolumn{3}{c}{ ADM } \\
\hline MLN & $24.3 \pm 1.6$ & $23.4 \pm 2.2$ & $56.1 \pm 3.4^{*}$ \\
Thymus & $16.4 \pm 2.1$ & $16.2 \pm 2.1$ & $51.3 \pm 3.1^{*}$ \\
Spleen & $41.4 \pm 1.9$ & $43.1 \pm 2.0$ & $75.2 \pm 4.6^{*}$ \\
GC & $16.9 \pm 0.8$ & $15.4 \pm 1.0$ & $71.4 \pm 6.5^{*}$ \\
Soleus & $50.9 \pm 2.3$ & $52.4 \pm 2.7$ & $34.2 \pm 3.2^{*}$
\end{tabular}

Table 5 - Mn-superoxide dismutase (Mn-SOD) activity $\left(x 10^{3}\right)$ in the lymphoid organs and muscles of adrenodemedullated (ADM), shamoperated and control rats.

Values are reported as means \pm SEM for 8 rats in each group. ${ }^{*} \mathrm{P}<0.01$ for comparison between $\mathrm{ADM}$ and sham-operated rats (Student $t$-test). MLN, Mesenteric lymph nodes; GC, gastrocnemius white portion.

\begin{tabular}{lccc}
\hline & $\begin{array}{c}\text { Control } \\
\left(\mu \mathrm{mol} \mathrm{min} \mathrm{min}^{-1} \mathrm{~g} \text { tissue fresh weight }{ }^{-1}\right)\end{array}$ \\
\hline MLN & $0.27 \pm 0.02$ & $0.32 \pm 0.02$ & $0.10 \pm 0.01^{*}$ \\
Thymus & $0.20 \pm 0.02$ & $0.22 \pm 0.01$ & $0.52 \pm 0.06^{*}$ \\
Spleen & $0.62 \pm 0.04$ & $0.60 \pm 0.02$ & $0.43 \pm 0.08^{*}$ \\
GC & $0.22 \pm 0.01$ & $0.21 \pm 0.01$ & $0.24 \pm 0.02$ \\
Soleus & $0.52 \pm 0.04$ & $0.53 \pm 0.02$ & $0.67 \pm 0.03^{*}$
\end{tabular}

Table 6 - Catalase activity $\left(\times 10^{3}\right)$ in the lymphoid organs and muscles of adrenodemedullated (ADM), sham-operated and control rats.

Values are reported as means \pm SEM for 8 rats in each group. ${ }^{*} \mathrm{P}<0.01$ for comparison between $\mathrm{ADM}$ and sham-operated rats (Student $t$-test). MLN, Mesenteric lymph nodes; GC, gastrocnemius white portion.

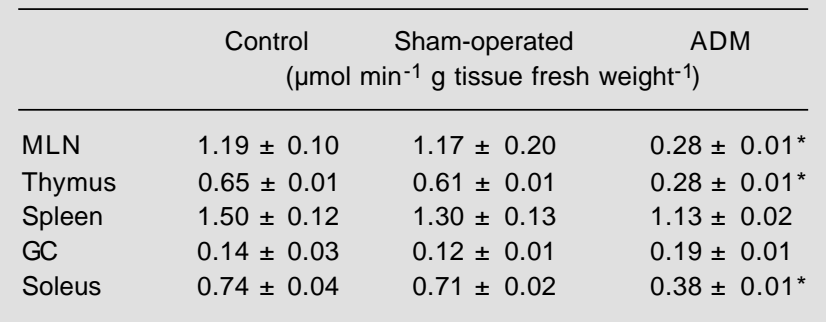


Table 7 - Glutathione peroxidase (GPX) activity $\left(x 10^{3}\right)$ in the lymphoid organs and muscles of adrenodemedullated (ADM), sham-operated and control rats.

Values are reported as means \pm SEM for 8 rats in each group. ${ }^{*} \mathrm{P}<0.01$ for comparison between $\mathrm{ADM}$ and sham-operated rats (Student $t$-test). MLN, Mesenteric lymph nodes; GC, gastrocnemius white portion; ND, not detected.

\begin{tabular}{lccc}
\hline & $\begin{array}{c}\text { Control } \\
\left(\mu \mathrm{mol} \mathrm{min}^{-1} \mathrm{~g} \text { tissue fresh weight }{ }^{-1}\right)\end{array}$ & ADM \\
\hline MLN & $3.10 \pm 0.19$ & $3.21 \pm 0.17$ & $\mathrm{ND}$ \\
Thymus & $4.00 \pm 0.64$ & $3.80 \pm 0.54$ & $\mathrm{ND}$ \\
Spleen & $4.40 \pm 0.10$ & $4.22 \pm 0.07$ & $\mathrm{ND}$ \\
GC & $5.40 \pm 0.14$ & $5.23 \pm 0.12$ & $\mathrm{ND}$ \\
Soleus & $6.50 \pm 0.18$ & $6.33 \pm 0.20$ & $\mathrm{ND}$
\end{tabular}

that adrenaline markedly stimulates glucose consumption and lactate production in incubated macrophages (34). The combined reduction in TCA cycle and pentose-phosphate pathway activity will reduce NADPH generating capacity. This may explain the observed reduction in TBARs concentration in the lymphoid organs and gastrocnemius muscle of ADM rats (Table 1). Epinephrine may stimulate metabolic pathways for NADPH production, which could increase TBARs concentration in the tissues. In addition, we have evidence that epinephrine can greatly stimulate macrophage $\mathrm{H}_{2} \mathrm{O}_{2}$ production via cAMP within one hour of addition of the hormone (23). Thus, epinephrine may increase NADPH production by allosteric (in this example) as well as by transcrip- tional/translational mechanisms.

Adrenodemedullation also markedly affected the activities of anti-oxidant enzymes. In summary, among the enzymes studied, the absence of the adrenal medulla raised the activity of $\mathrm{Cu} / \mathrm{Zn}-\mathrm{SOD}$ (Table 4), diminished that of catalase (Table 5) and abolished that of glutathione peroxidase (Table 7). The findings of a decrease in catalase activity and abolition of glutathione peroxidase activity due to adrenodemedullation led us to speculate that epinephrine physiologically regulates the activities of these enzymes in the lymphoid organs. In fact, there is evidence that epinephrine activates glutathione peroxidase in the heart, liver and kidney (35). Whether this effect is mediated by the increase in the concentration of oxygen reactive species (36) or is directly caused by the action of the hormone itself remains to be determined.

The present observations are consistent with the possibility that epinephrine might play a role in the oxidative stress of the lymphoid organs. Whether this fact represents an important mechanism for the establishment of impaired immune function during stress remains to be elucidated.

\section{Acknowledgments}

The authors are grateful to M. Carnelós Filho, J.R. Mendonça and G. de Souza for technical assistance.

\section{References}

1. Sharmanov AT, Aidarkhanov BB \& Kurmangalinov SM (1990). Effects of vitamin $\mathrm{E}$ deficiency on oxidative metabolism and anti-oxidant enzyme activity of macrophage. Annals of Nutrition and Metabolism, 34: 143-146.

2. Baxter M, Leslie R \& Reeves W (1983). The stimulation of superoxide anion production in guinea-pig peritoneal macrophages and neutrophils by phorbol myristate acetate, opsonized zymosan and IgG2-containing soluble complexes. Im- munology, 48: 657-665.

3. Butterick $C$, Baehner R, Boxer $L$ \& Jersild R (1983). Vitamin E - selective inhibitor of the NADPH oxidoreductase enzyme system in human granulocytes. American Journal of Pathology, 112: 287-293.

4. Bendich A \& Shapiro SS (1986). Effect of beta-carotene and canthaxanthin on the immune responses. Journal of Nutrition, 116: 2254-2262.

5. Corwin LM \& Gordon RK (1982). Vitamin $\mathrm{E}$ and immune regulation. Annals of the
New York Academy of Sciences, 393 437-451.

6. Chandra RK (1990). Cellular and molecular basis of nutrition-immunity interactions. In: Bendich A, Phillips M \& Tergerdy RP (Editors), Advances in Experimental Medicine and Biology. Plenum Press, New York and London.

7. Gougerot-Pacidalo MA, Fay M, Roche $Y$, Lacombe P \& Marquetty C (1985). Immune oxidative injury induced in mice exposed to normobaric oxygen: effects of 
thiol compounds on the splenic cell sulphydryl content and Con A proliferative response. Journal of Immunology, 135: 2045-2051.

8. Bendich A (1990). Antioxidant nutrients and immune functions. In: Bendich A, Phillips $M$ \& Tergerdy RP (Editors), $A d$ vances in Experimental Medicine and Biology. Plenum Press, New York and London.

9. Hassan NF \& Douglas SD (1990). Stressrelated neuroimmunomodulation of monocyte-macrophage functions in HIV-1 infection. Clinical Immunology and Immunopathology, 54: 220-227.

10. Miller AH, Spencer RL, Trestman RL, Kim C, McEwen BS \& Stein M (1991). Adrenal steroid receptor activation in vivo and immune function. American Journal of Physiology, 261: E126-E131.

11. Mason D (1991). Genetic variation in the stress response: susceptibility to experimental allergic encephalomyelitis and implications for human inflammatory disease. Immunology Today, 12: 57-60.

12. Fleming SD, Edelman LS \& Chapes SK (1991). Effects of corticosterone and microgravity on inflammatory cell production of superoxide. Journal of Leukocyte Biology, 50: 69-76.

13. Maridoneau-Parini I, Errasfa $M$ \& RussoMarie $F$ (1989). Inhibition of superoxide generation by dexamethasone is mimicked by lipocortin I in alveolar macrophages. Journal of Clinical Investigation, 83: 18836-18840.

14. Delahunt JW \& Mellsop G (1987). Hormone changes in stress. Stress in Medicine, 3: 123-143.

15. Maisel AS, Murray D, Lotz M, Rearden A, Irwin M \& Michel MC (1991). Propranolol treatment affects parameters of human immunity. Immunopharmacology, 22: 157-164.

16. Cremaschi GA, Fischer $P$ \& Boege $F$ (1991). B-Adrenoceptor distribution in murine lymphoid cell lines. Immunopharmacology, 22: 195-206.

17. Yu DTY \& Clements PJ (1976). Human lymphocyte subpopulations effect of epinephrine. Clinical and Experimental Immunology, 25: 472-479.

18. Landmann RMA, Muller $\mathrm{FB}$, Perini $\mathrm{CH}$, Wesp M, Erne P \& Buhler FR (1984). Changes of immunoregulatory cells induced by psychological and physical stress: relationship to plasma catecholamines. Clinical and Experimental Immunology, 58: 127-135.

19. Weicker H \& Werle E (1991). Interaction between hormones and the immune system. International Journal of Sports and Medicine, 12 (Suppl 1): 30-37.

20. Fry RW, Morton AR \& Keast D (1991). Overtraining in athletes, an update. Sports Medicine, 12: 32-65.

21. Cannon JG (1993). Exercise and resistance to infection. Journal of Applied Physiology, 74: 973-981.

22. Munck A, Guyre PM \& Holbrook NJ (1984). Physiological functions of glucocorticoids in stress and their relation to pharmachological actions. Endocrine Reviews, 5: 25-44.

23. Costa Rosa LFBP, Curi R, Murphy C \& Newsholme $P$ (1995). Effect of epinephrine and phorbol myristate acetate or bacterial lipopolysaccharide on stimulation of pathways of macrophage glucose, glutamine and $\mathrm{O}_{2}$ metabolism. Biochemical Journal, 310: 709-714.

24. Harris ED (1992). Regulation of antioxidant enzymes. Journal of Nutrition, 122: 625-626.

25. Almeida AF, Curi R, Newsholme $P$ \& Newsholme EA (1989). Maximal activities of key enzymes of glutaminolysis, glycolysis, Krebs cycle and pentose-phosphate pathway of several tissues in mature and aged rats. International Journal of Biochemistry, 21: 937-940.

26. Newsholme $P$, Curi R, Gordon $S$ \& Newsholme EA (1986). Metabolism of glucose, glutamine, long chain fatty acids and ketone bodies by murine macrophages. Biochemical Journal, 239: 121-125.

27. Costa Rosa LFBP, Cury Y \& Curi R (1992). Effects of insulin, glucocorticoids and thy- roid hormones on the activities of key enzymes of glycolysis, glutaminolysis, the pentose-phosphate pathway and the Krebs cycle in the rat macrophages. Journal of Endocrinology, 135: 213-219.

28. Marklund LS (1985). Direct assay with potassium superoxide. In: Greenwald RA (Editor), Handbook of Methods for Radical Research. CRC Press, New York.

29. Beutler E (1975). Red Cell Metabolism. Greene \& Straton, New York.

30. Maral J, Puget K \& Michelson AM (1977). Comparative study of superoxide dismutase, catalase and glutathione peroxidase levels in erythrocytes of different animals. Biochemical and Biophysical Research Communications, 77: 1525-1535.

31. Cooney GJ, Taegtmeyer $\mathrm{H}$ \& Newsholme EA (1981). Tricarboxylic acid cycle flux and enzyme activities in the isolated working rat heart. Biochemical Journal, 200: 701703.

32. Bergmeyer HU \& Bernt E (1974). Glucose-6-phosphate dehydrogenase. In: Bergmeyer HU (Editor), Methods in Enzymatic Analysis. Academic Press, London, 458-459.

33. Winterbourn C, Gutteridge JMC \& Halliwell B (1985). Doxorubicin-dependent lipid peroxidation at low partial pressure of oxygen. Journal of Free Radicals in Biology and Medicine, 1: 43-49.

34. Costa Rosa LFBP, Safi DA, Cury Y \& Curi $R$ (1992). Effect of epinephrine on glucose metabolism and hydrogen peroxide content in incubated rat macrophages. Biochemical Pharmacology, 44: 22352241.

35. Kolesnichenko LS, Kulinskii VI, las'ko MV Pensionerova GA \& Grudinina IUV (1994). Effect of insulin and adrenaline on the activity of enzymes of glutathione metabolism and glutathione concentration in rat organs. Problemy Endokrinologii, 40: 42-44.

36. Storz G, Tartaglia LA \& Ames BN (1990). Transcriptional regulator of oxidative stress-inducible genes: direct activation by oxidation. Science, 248: 189-194. 